\title{
The Influence of PBL Teaching Mode on Critical Thinking Ability for Non-English Majors under Network Environment
}

\author{
Ying Wang \\ Nanchang Institute of Technology, Nanchang City, Jiangxi Province, China, 330099
}

\begin{abstract}
In order to explore the effect of PBL teaching mode on the cultivation of critical thinking ability for non-English majors, this paper uses case analysis method to explain the process of applying PBL teaching mode to non-English Majors' College English course teaching, namely, preparation questions stage before class, classroom activity stage and classroom reflection section. Result: before teaching, there was no statistical difference between the two groups of students' CTDI-CV score and the scores of each item $(\mathrm{P}>0.05)$. After teaching, the total scores of CTDI-CV items in the test group were higher than those in the control group, the difference was statistically significant $(\mathrm{P}<0.05)$. The experiment shows that the PBL teaching mode is superior to the LBL teaching mode, which is conducive to improving students' critical thinking ability.
\end{abstract}

Keywords: PBL teaching mode; Non-English majors; Critical thinking; Influencing mechanism.

\section{Introduction}

Critical thinking ability (CT) covers the ability of interpretation, analysis, evaluation, speculation, interpretation and self-adjustment, and shows the truth, openness, analytical and tenacity that do not yield to authority, not to be blind. Cultivating critical thinking ability is not only the basis of information processing ability and independent learning ability, but also the prerequisite of innovative thinking. Therefore, cultivating critical thinking ability has become an important goal of teaching.

Problem-Based Learning (PBL) is a teaching strategy. Originated in the middle of 1960s, at the Medical College of McMaster University in Canada, Barrows carried out a teaching reform in order to improve teaching quality. Since then, PBL has been widely applied to engineering, construction, business, education and social work. Nelson puts forward a more comprehensive definition: PBL is a teaching strategy that begins with a question that requires students to solve a complex and confused problem that may be encountered in a real society in the form of group collaboration; the process of solving the problem can allow students to actively participate in the analysis of problems and review the knowledge that has been learned. Knowledge, identification of relevant facts, and the construction of new knowledge on this basis; the students will decide which issues are required by the group, which can be carried out by the individual and designed to solve the problem. In the study of critical thinking, almost all studies show that the teaching of critical thinking should be based on problem strategies to solve problems. By coping with various difficult problems,
PBL learning model makes learners produce critical thinking and creative thinking, which is called an excellent container for promoting thinking.

\section{PBL basic mode}

PBL teaching theory is a kind of learning method which emphasizes students' independent inquiry, that is, students choose to study projects or themes under the guidance of teachers, collect information, analyze information, acquire knowledge, apply knowledge, and solve problem learning activities in the way of research. Therefore, different from the traditional teaching theory, under the framework of PBL, students are not only the ability to recite, understand, master and retell the book knowledge, but also need to know how to use all kinds of information sources to find the information they need, and to analyze, sum up and refine the information, which can be accurately express their opinions and write academic papers in a standardized way based on the collection and extraction of information. PBL is an autonomous learning mode. It aims at giving full play to students' subjective initiative and cultivating their critical thinking ability. Under such a mode, students independently move from closed textbooks to open research resources, cooperate with each other, and conduct open exploration. Therefore, PBL has the characteristics of autonomy, research, openness and cooperation.

From the perspective of language teaching, some Western linguists also describe PBL. They think that PBL is a teaching activity base on project, it focuses on learner-oriented teaching methods, is a teaching model concerned with 
language and content learning, and teachers need to provide the learners with the opportunity to pay attention to the fluency and accuracy of language at different stages of the project.; students can collaborate with other members of the group to complete the project together; the evaluation of the project is based on process and results; the project is challenging and interesting to help the learners build self-esteem, self-confidence, improve participation initiative, and improve the language skills, professional knowledge and research of the learners. Stroller proposed 10 steps to follow in the implementation of PBL: (1) teachers and students jointly decide the theme of the project; 2) teachers and students jointly decide the final result of the project; 3 ) the joint construction project between teachers and students; 4) teachers give students the support of the language, skill and strategy needed in the process of information collection; 5) students collect information; 6) Teachers give students the support of the language, skills and strategies needed in the process of information analysis and extraction; 7) students collate and analyze information; 8) teachers provide students with the support of language, skills and strategies to display the results; 9) students display their results; 10) Students evaluate their results.

PBL emphasizes the students' research learning. Teachers are no longer the knowledge imparters in the traditional mode, but they become the managers, guides, guides, assistors and evaluators in student project research. Teachers should help students participate in learning and form partnerships with other students, finally, teachers and students complete projects in groups. In this process, students find information, acquire and apply knowledge. The teacher evaluates the students as an evaluator. Therefore, the PBL model is conducive to the development of teachers' education, classroom reform and innovation, which is conducive to the transformation of students' learning methods, and helps to cultivate the ability of autonomy, cooperation and inquiry learning; it can promote the students' critical thinking and self-reflection, the cultivation of the consciousness of the problem and the development of the ability to ask questions, and the mastery of knowledge. The cultivation of high-quality talents is conducive to the cultivation of learning interest and the development of comprehensive thinking ability.

\section{The experimental process that affects the cultivation of critical thinking ability for non-English majors under PBL teaching model}

\subsection{Research objects and groups}

In this paper, 63 people in communication department were selected and randomly divided into 30 groups, 33 in the control group. The students in the experimental group were randomly divided into 3 learning groups, there were 10 people in each group, and 1people were responsible for each group. There was no significant difference between the two groups when they entered school randomly. Theoretical hours, experimental hours, and teaching materials are all the same.

\subsection{Research method}

The test group adopted the PBL teaching model, the following steps were as follows: 1) rearranging the contents of the teaching materials; 2) choosing the suitable students' problems; 3) ask relevant experts to review, modify, compile the PBL learning manual; 4) send the content to student ahead of one weeks, and recommend relevant information to the students. Before class, students consult the data and discuss problems, and find the answers to the questions in the PBL learning manual. In the class, each group selected 1 representatives to speak, the other students added, when the opinions disagreed with each other, the instructed teachers give "arbitration"; when teachers and students met the controversial problems, and asked the relevant experts to answer them after class. After class, students must rearrange the class discussion and hand in PBL homework, and feedback to students after the teacher has read it. Each class according to the performance of each group, to give quantitative points, as an important reference for peacetime results. The traditional LBL teaching model was used in the control group.

\subsection{Evaluating indicator}

The article uses Professor Peng Mei's critical thinking tendency questionnaire (CCTDI) in California, combined with the Chinese cultural to form critical thinking scale (CTOI-CV) [3], which is mainly used to measure critical thinking ability. It includes 7 sub tables, namely, the truth quantization table, the open quantization table, the analytical quantized table, the systematic quantitative table, the quantitative table of critical thinking self-confidence, the curiosity quantizing table, and the maturity quantizing table. They test the characteristics of critical thinking as follows: seeking truth, opening ideas, systematization, analytical ability, critical thinking self-confidence, knowledge desire and cognitive maturity. CTDI CV has 70 items, using 6 score Likert quantization table format. Each item answers divided into 6 levels from "strong consent" to "strong disagreement". Positive entries are assigned 6, 5, 4, 3, 2, 1, negative entry reverse assignment [4], and the test time should not be less than $20 \mathrm{~min}$. The score of each subscale was 10 60 points, and the score less than 30 points showed no corresponding critical thinking emotion tendency; the score $>40$ points had corresponding critical thinking ability, and the score $>50$ points showed that the corresponding critical thinking emotional tendency was strong. The total score of the CTDI CV scale was 70 420 points, and the score was less than 210 indicating that there was no corresponding critical thinking emotional tendency; 211 280 points were considered to be weak in critical thinking; the $>280$ points showed positive critical thinking; and the 350 points were considered to be stronger in critical thinking. Professor Peng Meici tested the reliability and validity of CTDI-CV. The comprehensive content validity index was 0.89 , and the efficiency coefficients of each subclass were 0.60 to 1 , which the open thought, the truth and analysis ability were evaluated as 1 , the confidence and systematization of critical thinking were evaluated 0.9 , and the cognitive maturity was evaluated. The 
thirst for knowledge was evaluated 0.6 and 0.8 respectively. The $\alpha$ value of CTDI-CV is 0.90 , and the $\alpha$ value of the trait is 0.54 to 0.77 .

\subsection{Analysis of experimental results}

The two groups of students filled out CTDI-CV before and after teaching, the test group issued 30 quantitative tables, 30 copies of effective questionnaires were recovered, 33 questionnaires were issued in the control group and 33 valid questionnaires were recovered.

Table 1. Comparison of two group students' critical thinking ability before and after teaching.

\begin{tabular}{c|c|c|c|c}
\hline \multirow{2}{*}{} & \multicolumn{2}{|c|}{ Control group $(\mathrm{n}=33)$} & \multicolumn{2}{c}{ Experience group $(\mathrm{n}=30)$} \\
\cline { 2 - 5 } & Before teaching & After teaching & Before teaching & After teaching \\
\hline Seek the truth & $45.7 \pm 6.2$ & $45.5 \pm 5.2$ & $46.2 \pm 6.3$ & $48.6 \pm 8.8$ \\
\hline Open thought & $40.2 \pm 6.7$ & $36.6 \pm 6.3$ & $42.3 \pm 5.9$ & $52.6 \pm 5.9$ \\
\hline Systematization ability & $42.1 \pm 6.6$ & $43.0 \pm 5.8$ & $38.5 \pm 6.4$ & $48.6 \pm 7.3$ \\
\hline Analytical ability & $36.2 \pm 5.9$ & $40.1 \pm 4.8$ & $42.6 \pm 7.5$ & $44.2 \pm 5.5$ \\
\hline Self-confidence & $41.6 \pm 6.2$ & $42.3 \pm 6.6$ & $46.5 \pm 5.6$ & $46.6 \pm 6.2$ \\
\hline Thirst for knowledge & $38.2 \pm 6.8$ & $33.3 \pm 5.6$ & $40.2 \pm 8.8$ & $49.9 \pm 5.1$ \\
\hline Cognitive maturity & $43.2 \pm 6.9$ & $35.8 \pm 6.8$ & $41.8 \pm 5.6$ & $51.2 \pm 5.9$ \\
\hline Total score & $287.2 \pm 6.5$ & $276.6 \pm 5.9$ & $298.1 \pm 6.6$ & $341.7 \pm 6.4$ \\
\hline
\end{tabular}

Note: $\overline{\mathrm{x}} \pm \mathrm{s}($ Mean \pm standard deviation)

Before teaching, the CTDI-CV scores of the two groups were all greater than 280 points, indicating that two groups of students had positive critical thinking ability. However, the two groups were less than 40 points in their analytical ability and thirst for knowledge, and the cognitive maturity of the experimental group was also less than 40 points. There was no significant difference between the experimental group and the control group ( $\mathrm{P}>0.05)$. After teaching, the CTDI -CV total score of test group was higher than the control group, the difference was statistically significant $(\mathrm{P}<0.05)$, and the scores of open thought, analytical ability, systematization, knowledge desire and cognitive maturity in the scores of each project were higher than those in the control group, and the difference had the significance of statistics $(\mathrm{P}<0.05)$.

In this study, there was no significant difference between the test group and control group. After teaching, the total score of CTDI-CV in the experimental group was higher than that before the teaching, while the total score of CTDI-CV in the control group was lower than that before the teaching. The total CTDI-CV score of the test group was higher than that of the control group. The difference between the two groups was statistically significant. The use of the PBL teaching model in the college foreign language teaching was beneficial to the cultivation of students' criticism.

\section{The influence mechanism of PBL teaching mode on critical thinking ability of non-English majors}

\subsection{The rationality of classroom design}

Reasonable classroom design has a significant impact on whether the PBL teaching mode can guide non English majors to produce critical thinking ability. The rationality of classroom design is reflected in the setting of questions before class, introduction and reflection of problems. Before the teaching, the problems set before the class not only need to be able to fully stimulate the students' desire for knowledge, but also can cultivate the students' divergent thinking and knowledge extension ability. In the process of College English classroom teaching, teachers should correctly guide students to ensure that students can correctly predict and reason information so as to make correct judgments. Before the end of the class, the teacher guides the students to think deeply about the problems and contents, so as to comprehensively train the students' critical thinking ability.

\subsection{The critical thinking ability of teachers themselves}

The teacher's critical thinking ability affects the setting of the teaching problem. The teacher's questions must have the value and significance of the discussion. Secondly, whether the teacher can guide the students to carry out the extension of the problem. Teachers need to correctly guide students to participate in the discussion of problems, and gradually guide students to discuss problems. Finally, whether teachers can lead students to correct reflection and summarization after class teaching, and shape students' critical thinking ability.

\subsection{The student's own critical initiative}

PBL teaching mode emphasizes cooperative learning, which can reduce students' anxiety, thus providing a favorable learning psychological environment for students' learning. However, the students' own psychological environment is different, which will inevitably affect the effect of PBL teaching. Secondly, different students' critical initiative is different, the interest in the curriculum is different, and the students who are highly interested in the class can more easily accept the PBL teaching mode.

\section{Conclusion}

The extensive application and popularization of PBL teaching mode in the world is a breakthrough in modern education and teaching methods, which provides a more effective way of 
education and teaching for the cultivation of high level talents. Compared with the traditional instillation teaching mode, the PBL teaching model has more advantages. It can fully mobilize the students' enthusiasm in the practice of College English Teaching for non-English majors, and have a positive influence on improving the students' critical thinking ability, so that students can absorb new knowledge and promote themselves while they are absorbing new knowledge. In order to promote the further development of PBL teaching model, teachers should also pay more effort to improve their critical thinking ability, so as to design a more reasonable PBL mode of teaching class.

\section{Acknowledgements}

The subject is teaching reform of Nanchang Institute of Technology in 2017 "The influence of PBL teaching mode on critical thinking ability of non-English Majors". Project number: 2017JG011.

\section{References}

1. Li Li, Du Jiemin. Research on PBL teaching mode of academic English under the background of College English Teaching [J]. Foreign language teaching, 2014 (05): 55-58.

2. Li Zhengjian, Li Yingxin. A study on the implementation of critical thinking education for Chinese College Students $[\mathrm{J}]$. The theory and practice of foreign language teaching, 2015 (03): 49-58.

3. Peng Meici, Wang Guocheng, Chen Jile, and so on. Reliability and validity of critical thinking scale $[\mathrm{J}]$. Chinese Journal of nursing, 2004, 39 (9): 644-647.

4. He Yingxia, Gu Pei, Chen Liqun. Study on the influence of PBL teaching method on critical thinking ability of nursing undergraduates $[\mathrm{J}]$. Nursing education research, 2009, 23 (4B): 1004-1005. 